\title{
Military thoracic gunshot wounds: A systematic review
}

DOI 10.2478/jms-2021-0009

Received July 05, 2020; Accepted July 10, 2021

\begin{abstract}
A systematic review of the literature was carried out using the Preferred Reporting Items for Systematic Reviews and Meta-Analyses (PRISMA) method to investigate the frequency of military thoracic gunshot wounds (GSWs) and deaths in combat theatres since World War Two (WW2). An electronic database search of World of Science, Scopus, Science Direct, PubMed and Microsoft Academic was conducted using the keywords 'combat, casualties, thorax, gunshot, and military' to identify peer-reviewed journals and conference papers on the topic. Twenty-three sources relevant to this review were identified and covered multiple theatres of operation. While there is a downward trend in the frequency of thoracic GSWs and fatalities likely due to the improvement of body armour, the improvement in medical treatment and increased frequency of improvised explosive devices (IEDs), the review shows that the advancement has not removed the likelihood of thoracic GSWs, which still accounted for approximately $15 \%$ of all thoracic injuries in the most recent combat theatres. The systematic review identifies that GSWs of the thorax continue to be a risk in military theatres and therefore, medical personnel should be aware of the frequency and severity of thoracic GSWs and should be prepared to treat these life-threatening injuries, as timely intervention is essential.
\end{abstract}

Keywords: military, thoracic, gunshot, systematic review

\section{Introduction}

Gunshot wounds (GSWs) are a source of severe traumatic injuries and accounted for $31 \%$ of military fatalities

\footnotetext{
*Corresponding author: Amy Pullen, Department of Orthopaedics and Musculoskeletal Medicine, University of Otago, Christchurch School of Medicine, P.O. Box 4545, Christchurch 8140, New Zealand, E-mail:a.pullen@dta.mil.nz

David Kieser and Gary Hooper, Department of Orthopaedics and Musculoskeletal Medicine, University of Otago, Christchurch School of Medicine, Christchurch 8140, New Zealand
}

of UK soldiers from January 2009 to December 2013 (Penn-Barwell et al. 2016).

The thoracic cavity contains vital organs such as the heart, lungs and major arteriovenous structures and is protected by the thorax, which is made up of the thoracic spine, the rib cage and the sternum; and the diaphragm separates the thorax from the abdomen. The total body surface area of an adult's thorax is approximately $18 \%$ (Moore et al. 2019). Historically, in combat theatres, thoracic GSWs accounted for a large proportion of mortality and morbidity. In more recent combat theatres, the thorax has remained a preferred target, thought to be due to its large surface area and vital internal organs. Therefore, protecting the thorax from penetrating injury remains of critical importance in austere environments.

The recognition of the importance of protecting the thorax has driven the evolution of body armour. During World War One (WW1) and World War Two (WW2), body armour was not worn; in the Korean and Vietnam wars flak vests were introduced; and more recently, thoracic protection has advanced to the capacity of defeating $7.62 \mathrm{~mm}$ calibre ammunition and in some cases armour-piercing ammunition.

However, like the evolution between predator and prey, munition design has evolved to combat advances in body protection. Nowadays, munitions include enhanced penetration projectiles to overcome body armour. Therefore, despite advances in body armour, GSWs of the thorax remain a common injury.

This systematic review aims to investigate military thoracic GSW frequency and subsequent fatalities reported since WW2, and to inform and direct future research in crucial areas such as medical treatment and protection.

\section{Method}

A systematic review of the English literature concerning military thoracic GSWs and fatalities was carried out by two separate researchers following the Preferred Reporting Items for Systematic Reviews and Meta-Analyses (PRISMA) guidelines. An electronic database search of 
World of Science, Scopus, Science Direct, PubMed and Microsoft Academic was conducted using the keywords 'combat, casualties, thorax, gunshot, and military' to identify peer-reviewed journals and conference papers on the topic. The reference lists from the included studies were searched to identify additional studies.

The inclusion criteria were: (1) Reporting on military (combat) casualties; (2) Gunshot injuries; (3) Anatomical region described as the thorax, chest or back if it pertained to the thoracic region; (4) Minimum of one casualty or fatality from a thoracic gunshot; (5) Reported since WW2; (6) Written in English. Exclusion criteria were: (1) Non-gunshot trauma to the thorax; (2) Civilian gunshot injuries; (3) Unable to distinguish between mechanisms of penetrating injury; (4) Reported before WW2.

The primary outcome of this review was to determine the frequency of thoracic GSWs and fatalities in military personnel.

The modified Newcastle-Ottawa scale was used to determine the methodological quality and focused on evaluating if the study was representative of the exposed cohort, the method of ascertaining exposure data, the degree of comparability of the data and whether an assessment of the outcome was presented and quality ratings given (poor, fair or good). The modified Cochrane tool was used to assess the risk of selection, performance, detection, attrition and reporting bias of the included studies with each metric given a risk of bias score (low, medium and high) and the scores totalled to determine the overall risk of bias.

The risk of population bias in this systematic review is expected due to the military hospitals also treating civilians; therefore, power analysis was not performed. However, a narrative description of the theatre and injury occurrence was performed to reduce the possible effects of study overlap. Qualitative synthesis in clinical outcome was not included in this systematic review due to the lack of long-term outcomes and severity.

The studies were further reviewed to determine the dates and the location of the combat theatre reported, the population involved, the number of thoracic GSW, the percentage of GSW the thorax accounted for or alternatively the percentage of thoracic injuries that GSW accounted for, the number and/or percentage of fatalities from thoracic GSW and any pertinent remarks to the study.

\section{Results}

The search criteria identified 224 articles, including 218 journal articles, one report, one conference proceeding and four chapters from one book. After implementing the inclusion and exclusion criteria, 23 studies were included for final review. Most data sources were discarded due to their datasets not differentiating between body areas and/or between the mechanism of injury, with penetrating injury used to classify both explosive fragmentation and gunshot injury. No other systematic reviews on this subject were identified. (Figure 1).

The quality of the studies was predominantly fair (10/23), with the remaining studies being split between poor (5/23) and good (8/23) quality. However, due to the lack of detail in some population descriptions between military and civilians, and differences in data reporting,

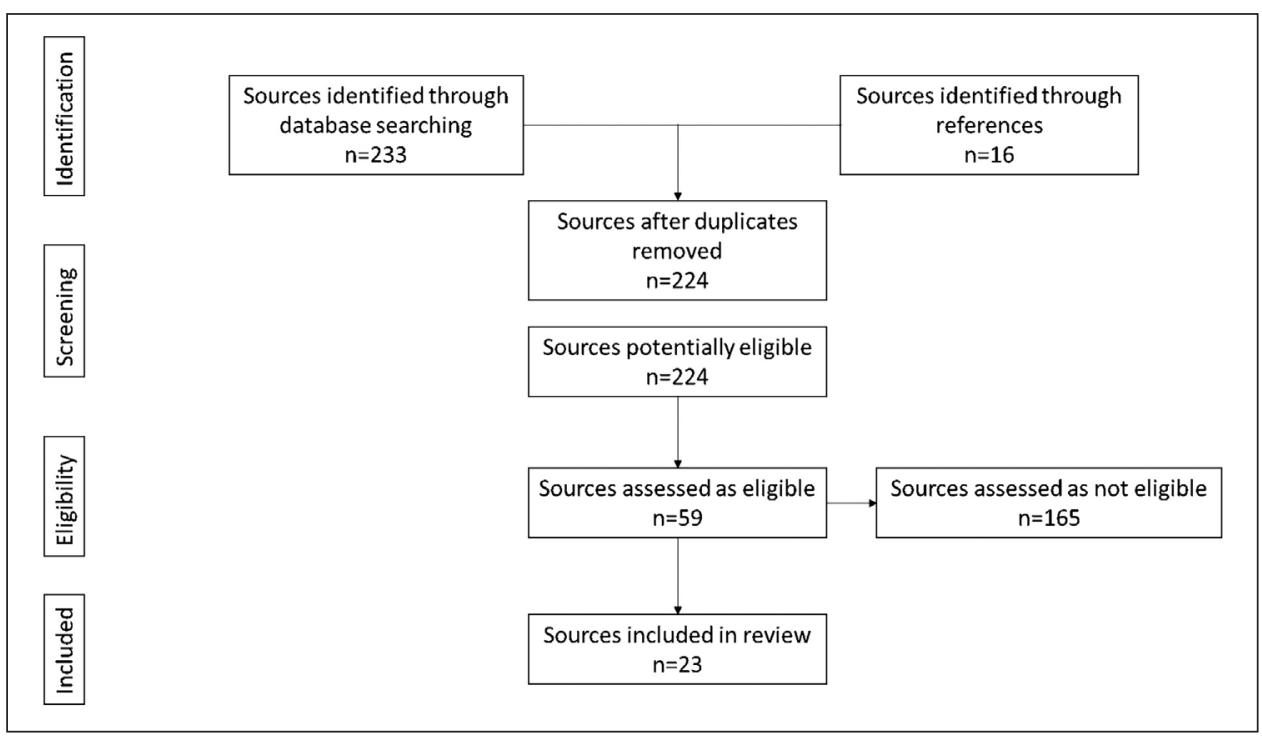

Fig. 1: PRISMA flow diagram. 
the majority of studies have been classified as having an unclear risk of bias (16/23), with the remaining studies being split across a low risk of bias (4/23) and a high risk of bias (3/23). This essentially means that most of the studies are missing information which makes the studies difficult to assess.

When comparing the studies that had a low risk of bias, the data showed an exponential downward trend in the frequency of thoracic GSW before levelling off and a decrease in the percentage of fatalities from thoracic GSW, as can be seen in Figure 2. This frequency of casualties reduces from 18 casualties per month from thoracic GSW (rounded to nearest casualty) and 57.1\% fatalities in New Georgia - Burma to 1 casualty per month (rounded to nearest casualty) and $27 \%$ fatalities in Iraq and Afghanistan. If this analysis is extended to include studies that had an unclear risk of bias, when using data sets that can be compared, the downward trend in fatalities can still be seen; however, this is not as clear in the frequencies of casualties (see Figure 3). Unfortunately, it was not possible to include all studies with an unclear risk of bias in this comparison due to the limited availability of data. This includes uncertainty if the number/percentage of fatalities is based on the number of gunshot fatalities that are attributed to thoracic GSW, or if they are based on the number of thoracic GSWs that were fatal and civilian injuries being included in the data set.
The studies included after the PRISMA process and data obtained for military, combat, thoracic gunshot injuries are summarised in Table 1.

\section{Discussion}

While the data is limited to only a small number of combat theatres and only provides information on specific nationalities and services, this is the first study to summarise and provide insight into the frequency of thoracic GSWs and subsequent fatalities over the last 80 years. The results of this study show that there is a clear downward trend in the percentage of fatalities and an exponential reduction in the frequency of casualties from thoracic GSW when considering studies that have a low risk of bias. These declines can be attributed to (a) the evolution of body armour, including the design, body surface coverage area and an improvement in body armour standards; (b) improvements in time of evacuation of casualties from the point of wounding to surgical care; and (c) improvement in medical techniques. Furthermore, the change in warfare giving way to asymmetric conflicts-which are characterised by the widespread use and increased frequency of improvised explosive device (IED) injuries rather than GSWs-will also have contributed to the decline in thoracic GSW.

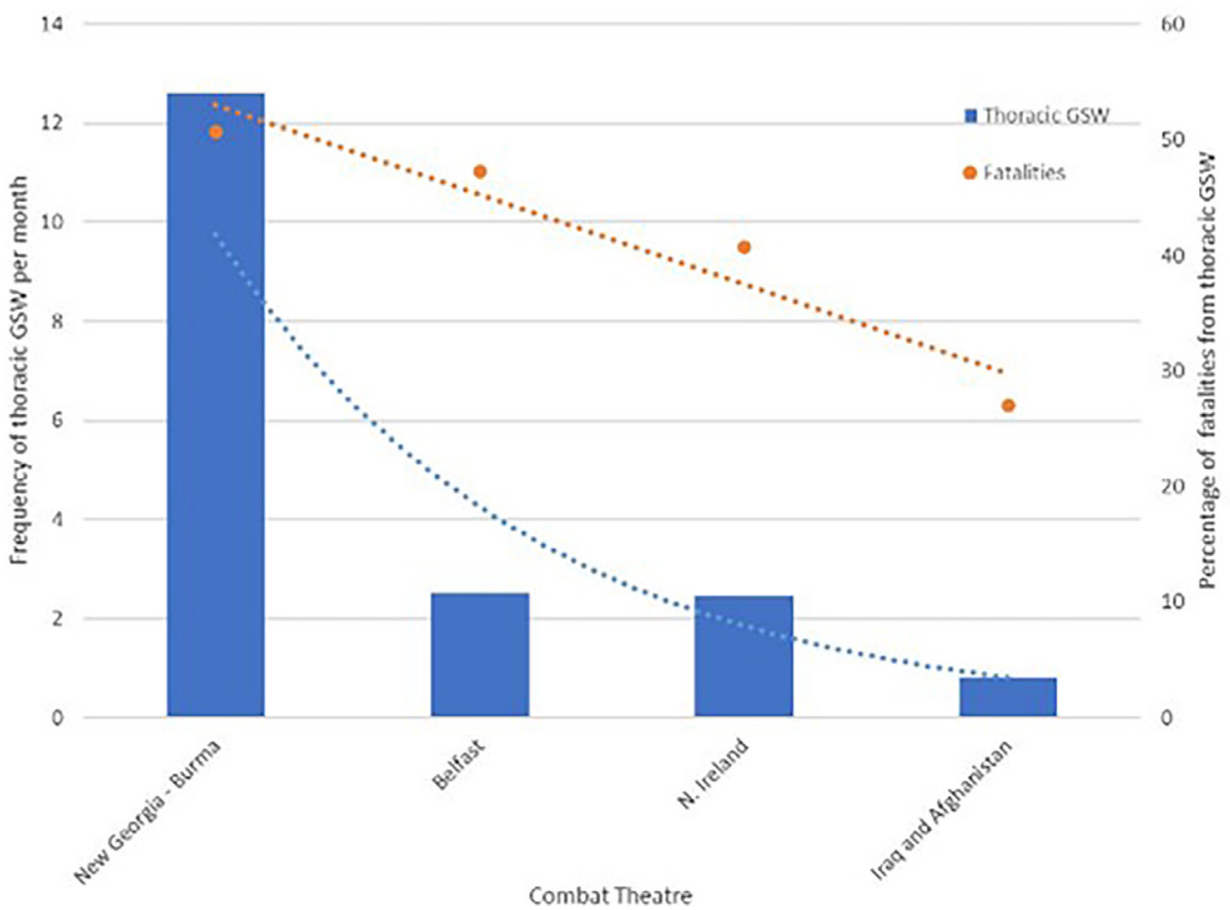

Fig. 2: Frequency of thoracic gunshot injuries per month and percentage of fatalities from thoracic GSW for studies with a low risk of bias. 


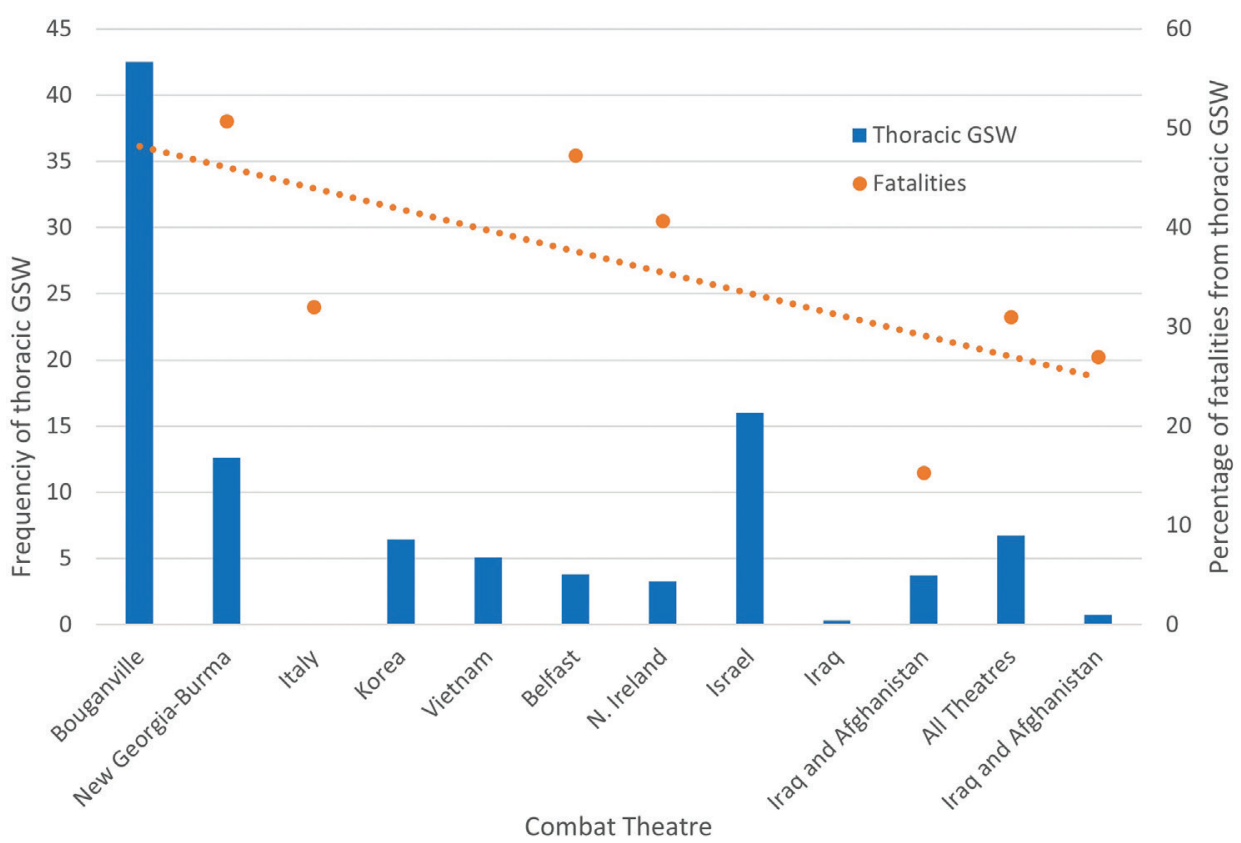

Fig. 3: Frequency of thoracic gunshot injuries per month and percentage of fatalities from thoracic GSW for studies with a low and unclear risk of bias.

\subsection{The evolution of body armour and the subsequent effect it had on thoracic GSW}

\subsubsection{Body amour design}

Body armour designs have changed significantly over the last 80 years from $1 \mathrm{~mm}$ thick manganese steel chest plates issued to Airborne forces in WW2, to M1952 flak jackets in Korea, followed by the M-69 Fragmentation Protective Body Armour in Vietnam and were continued to be worn during the start of the troubles in Northern Ireland (Tobin and Iremonger 2006; Carr and Lewis 2014). The M1952 and M-69 flak jackets did provide a certain level of protection against fragmentation and shrapnel; however, this level did not encompass protection against high-velocity projectiles, and therefore the frequency of thoracic gunshot injuries and the percentage of fatalities from thoracic GSW continued to remain high.

In 1965 para-aramid fibres were discovered and in 1972 they were commercialised by Dupont as Kevlar and were seen to offer ballistic protection from handguns. Para-aramids are still used in both military and police body armours today.

In the late 1970s the UK Forces were issued with Individual Northern Ireland Body Armour (INIBA), which not only offered protection from fragmentation and shrapnel but also protection against high-velocity projectiles using front and rear hard ceramic plates (Breeze et al. 2021). This would have led to reduction in the number of thoracic GSW and subsequent fatalities.
Meanwhile, the US military issued the Personal Armor System for Ground Troops (PASGT), which remained in service till the early 2000s. PASGT was designed to provide better protection against fragmentation and saw the move away from ballistic nylon to Kevlar by the US military (Roberts and Bullian 1993).

In 1991, the First Gulf War (GW1) saw Enhanced Combat Body Armour (ECBA) issued to UK Forces, which incorporated two ceramic hard armour plates with soft body armour (Carr and Lewis 2014). GW1 saw the widespread use of body armour for the first time with ECBA and PASGT being worn. (Brayley 2011).

In 2003 the US military issued Interceptor body armour (IBA), which consisted of an outer tactical vest that provided protection against fragmentation and handgun bullets, whilst the two Small Arms Protective Inserts (SAPI plates) provided protection up to $7.62 \mathrm{~mm}$ Full Metal Jacket (FMJ) bullets (Brayley 2011). The UK Forces continued to wear ECBA until 2006 and the introduction of OSPREY. The OSPREY plates provided better coverage and higher performance than the ECBA plates and provided an enhanced multi-hit capability, and the ECBA plates were repurposed as side plates to increase coverage area (Carr and Lewis 2014, Breeze et al. 2017). This protection from high-velocity bullets would have certainly led to a decrease in the number of thoracic GSW, as a large percentage of bullet threats seen in combat theatres were defeated.

The US forces issued the Improved Outer Tactical Vest (IOTV) in 2007, which saw enhanced SAPI (ESAPI) 


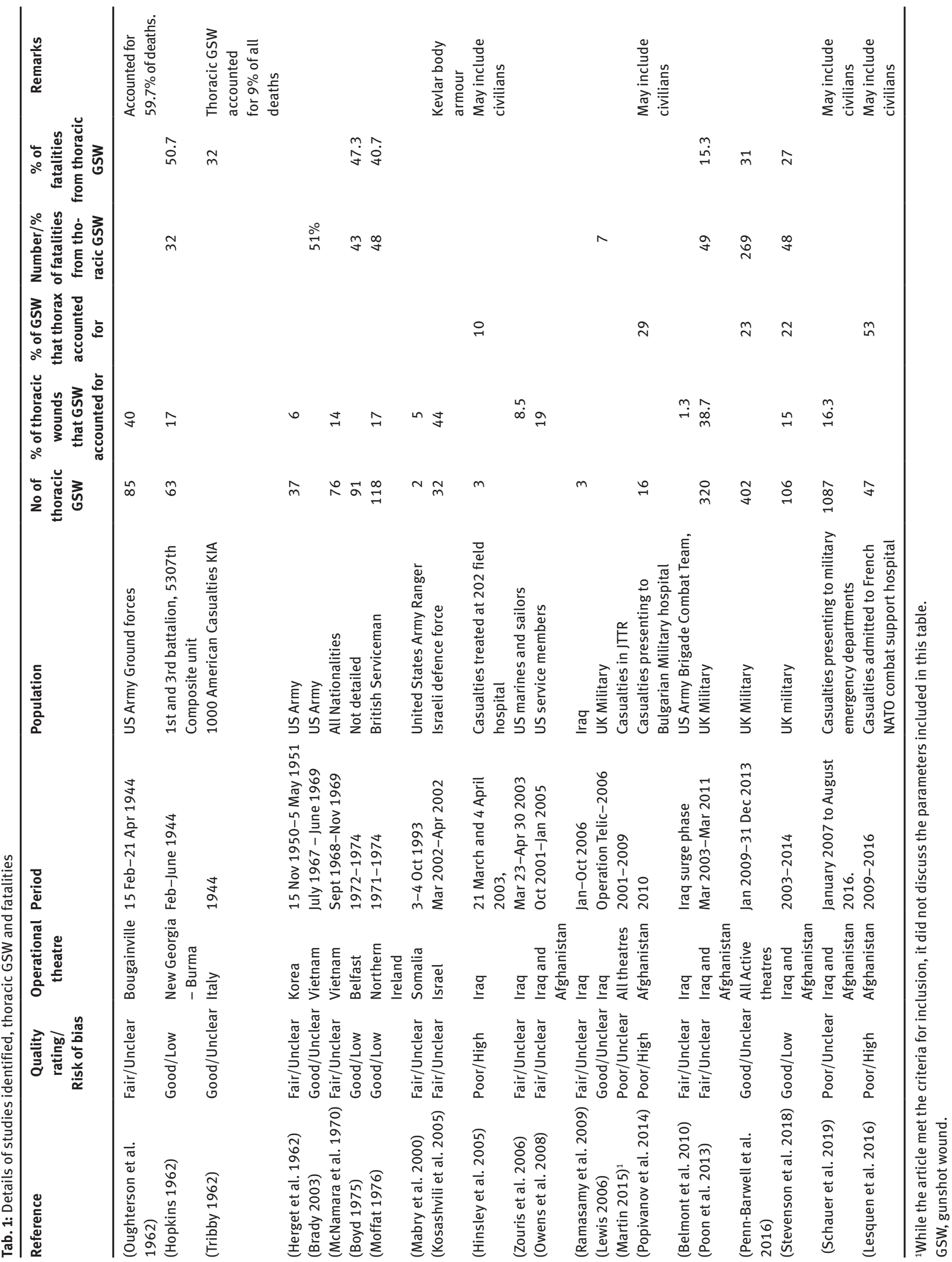


plates made from boron carbide that covers critical areas of the torso and provides protection from armour-piercing ammunition, and also features enhanced side ballistic inserts (ESBI) (Brayley 2011).

In 2016 the UK forces were issued VIRTUS scalable tactical vests, which allow the user to scale their protection level depending on the threat. They can be worn in several configurations including no armour, soft armour made of composite granular materials or a full armour system comprising of soft armour and hard ballistic plates (Lewis and Clarke 2018).

\subsubsection{Body armour coverage}

The original flak jacket fielding in Korea and Vietnam protected the thorax and the abdomen; however, during the 1970s it was recognised that some anatomical structures are more susceptible than others. This led to changes in design to provide the more susceptible anatomic structures extra protection. The soft armour continues to cover the whole thorax and abdomen as it is primarily designed to protect against fragmentation. The INIBA and ECBA plates covered the heart and mediastinum and were developed based on the prevalent threat and favourable condition of medical attention being available within $20 \mathrm{~min}$ during the Northern Ireland conflict. The ceramic plates used in the OSPREY system were refined based on the time to medical care being 1-2 $\mathrm{h}$, and in addition to the heart and the mediastinum, also protected the spleen and the liver (Breeze et al. 2016a,b).

ECBA plates have been used in OSPREY and VIRTUS to provide side protection and have been shown to already be optimised to provide side protection despite not being designed for this purpose (Breeze et al. 2021). It has also been recommended that a range of plate sizes should be used to optimise the coverage and effectiveness of body amour (Breeze et al. 2016a,b).

SAPI plates come in five sizes (extra-small to extralarge) designed to optimise fit and comfort for the user whilst providing suitable coverage for a range of body sizes and shapes.

More recently Breeze et al. have defined the essential coverage areas whose structures are likely to result in death within 60 min of significant injury unless damage control surgery (DCS) is received. These areas are defined as 'Heart, Mediastinal great vessels, Superior vena cava, Inferior vena cava, Pulmonary arteries and veins, Aorta, Brachiocephalic artery and veins, Left common carotid artery, Subclavian artery and vein, Iliac arteries and veins, Liver, Spleen, and Intrathoracic trachea' (Breeze et al. 2020).

\subsubsection{Body armour standards}

Body armour standards were introduced by the National Institute of Justice in 1972 with other standards such as the NATO Allied Engineering Publication 2920 also being developed over time. The purpose of the standards is to ensure that body armours offer an adequate level of protection against the threats that are tested. This not only ensures that high-velocity bullets are stopped but also that back face deformation of the body armour does not cause excessive blunt force trauma (Carr and Lewis 2014).

Military body armour is procured in accordance with the relevant national authority threats and specifications and therefore this ensures that the most common rounds in combat theatres are defeated and consequentially the number of thoracic GSW and subsequent fatalities are reduced.

\subsubsection{Medical response times}

During WW2, due to the complexities of evacuation and the sheer volume of casualties it could take between $12 \mathrm{~h}$ and $15 \mathrm{~h}$ for a casualty to be triaged and provided the necessary care. Based on the experiences of WW2, a Mobile Army Surgical Hospital (MASH) was put in place by the US Army for the Korean War. The MASH provided resuscitative surgical care within 10 miles of the front line and was supported by helicopter ambulances allowing casualties to be treated in 3-12 h of wounding and subsequently the mortality rates of all injuries were reduced. The use of helicopters in the medical evacuation was continued during the Vietnam War and the process improved. The helicopters transported casualties directly to full-service hospitals and reduced the treatment time to $60 \mathrm{~min}$ and ensured that treatment was provided within what is considered the golden hour (Manring et al. 2009).

Due to the changes in warfare, MASH hospitals were shown to be unsuitable during the GW1. This led to the formation of Combat Support Hospitals (CSH), with the new CSH first being used in 2003 in Iraq, and more recently the US has used a system that involves five levels of care, ranging from battalion aid stations to stateside trauma centres and a medical response time of 30-90 min (Manring et al. 2009).

Casualty evaluation timelines of UK forces are based on the NATO Allied Joint Publication (AJP) 4-10: Allied Joint Doctrine for Medical Support. The first version published in 2006 stated that battlefield advanced trauma and resuscitation techniques occur within $1 \mathrm{~h}$, DCS 
within $2 \mathrm{~h}$ and any further surgical procedures within $4 \mathrm{~h}$ (1-2-4 principle). An update to medical timelines was published in 2010, and called for first aid within $10 \mathrm{~min}$, skilled medical aid in $1 \mathrm{~h}$ and DCS in $2 \mathrm{~h}$. This was formalised in the 2015 update of the AJP 4-10 and became known as the 10-1-2 principle. However, the UK followed 10-1-2(2) +2, where the (2) is time taken to deliver DCS and the +2 is evacuation to deployed hospital care (DHC) for in-theatre surgery. The AJP 4-10 was updated in 2019 to follow these time frames but the +2 refers to further surgical, diagnostic, specialist care etc. being made within $2 \mathrm{~h}$ of tactical evacuation after DCS (Scallan et al. 2020).

The Medical Emergency Response Team (MERT) was formed due to the lack of secure road routes in Iraq and Afghanistan and allows medical interventions to be delivered that would normally be restricted to hospital facilities and can also be attributed to the decrease in fatalities (Keene et al. 2017).

\subsubsection{Improvement in medical interventions}

Improvements in medical techniques are wide-ranging but the key improvements have come in the form of infection treatment, haemostatic resuscitation and thoracic wound treatment.

Penicillin was first discovered in 1928 by Alexander Fleming, but it was not successfully used as a treatment to treat infections until 1942. The first large-scale use of it was not carried out until the D-Day invasions in 1944 and the Korean and Vietnam wars saw penicillin used in conjunction with streptomycin. The treatment of infection would have led to a reduction in the number of fatalities of thoracic GSW, but it was likely that during these conflicts many fatalities occurred before infection became a contributing factor. This is highlighted by broad-spectrum antibiotics not generally being administered in early treatment during the Iraq and Afghanistan conflicts (Manring et al. 2009).

Whole blood transfusions were introduced in 1944 and military blood programmes were established in 1953. Since the 1980s, whole blood has been separated into packed red blood cells (PRBC), fresh frozen plasma (FFP), platelets and cryoprecipitate. This allows specific components of blood to be administered without the risks of using whole blood and a ratio of 1:1:1 (platelets: FFP: PRBC) has been shown to improve mortality. Once bleeding is controlled, a more tailored approach is used to improve blood volume and pressure. Coagulopathy is assessed and any intervention needed is delivered. Tranexamic acid (TXA) is administered within $3 \mathrm{~h}$ and has also been shown to significantly reduce mortality in trauma bleeding casualties (Keene, et al. 2017).

Thoracic wound treatment has evolved from needle aspiration in WW2, to thoracentesis during the Korean and Vietnam wars, to tube thoracotomy in the 1980s, to more modern techniques including using vented chest seals, needle thoracentesis and simple thoracostomy, which has been shown to reduce the risk of pneumothorax (Kotora et al. 2013, Littlejohn 2017) and would have subsequently reduced the number of fatalities.

\subsubsection{Study limitations}

This study has several limitations. Firstly, the reporting of patients injured varies; for example, Schauer's study (Schauer et al. 2019) showed a significant increase in the number of casualties presenting at military emergency departments with thoracic GSWs in Iraq and Afghanistan. Hinsley's study (Hinsley et al. 2005) also showed an increase in the number of casualties presenting to the field hospital in the first 2 weeks of Operation Telic; however, both of these studies may have included unprotected civilian casualties. In contrast, Koshashvilli's study (Kosashvili et al. 2005) also showed an increase in the frequency of casualties suffering from thoracic GSWs; however, it should be noted that the majority of casualties were only wearing Kevlar body armour, which offers very little protection against high-velocity bullets. Secondly, the format of the data in the sources is varied, ranging from the percentage of all injuries, percentage of thoracic injuries and percentage of GSWs. While some sources provided detailed information, many sources did not. Thirdly, the included studies rarely detailed if body armour was being worn and if so the type of armour, and therefore, it cannot be determined if the development of body armour alone has directly reduced the mortality from these injuries. Fourthly, it is unknown if the studies include fatalities that occurred before treatment could be received, or if injuries that did not require hospital treatment are captured. Lastly, it is difficult to make comparisons between the combat environments because of the way in which information is presented and many studies having an unclear bias; therefore, only broad general observations can be made.

However, despite these limitations, it is clear that GSWs to the thorax remain a credible risk. This review confirms that advancements in body armour have not eliminated the threat of thoracic GSW, which still account for approximately $15 \%$ of all thoracic injuries in the 
most recent combat theatres (Stevenson, Carr et al. 2018, Schauer, Naylor et al. 2019). Thus, roles 1 and 2 medical personnel should be aware of the frequency and severity of thoracic gunshot injuries and should be prepared to treat these life-threatening injuries.

\subsubsection{Future work}

Future systematic review work should include the inclusion of injuries caused by fragmentation due to the change in the nature of warfare and IEDs being a prevalent threat. It should also include sensitivity analysis to determine the effects of including studies with an unclear risk of bias on the overall analysis and observations made.

With the developments of new materials and armour that can protect against armour-piercing ammunition, further research should be carried out to look at the tradeoffs between protection and mobility and how improved operability can subsequently improve survivability.

With the changing face of combat, the traumatic injuries incurred are likely to change; thus, future studies should focus on these changes to optimise the prevention and treatment of casualties.

\section{Conclusion}

This systematic review identifies that thoracic GSW continues to present a risk to military personnel despite the improvement of body armour, evacuation times, medical techniques and the changes in warfare. Therefore, medical personnel should be prepared to treat these life-threatening injuries and further research should be carried out to reduce thoracic GSW, if possible.

\section{Declarations}

Not applicable.

\section{Funding}

Not applicable.

\section{Competing interest}

The authors declare that they have no conflict of interest.

\section{Ethical approval and consent to participate}

Ethical approval was not needed for this systematic review.

\section{Consent for publication}

Not applicable.

\section{Availability of data and materials}

Supplied as additional files or within the text.

\section{Code availability}

Not applicable.

\section{Authors' contribution}

Amy Pullen and David Kieser developed the criteria. Amy Pullen carried out the review. David Kieser and Gary Hooper supervised the work, verified the analytical methods and reviewed the results. The first draft of the manuscript was written by Amy Pullen and all authors commented on previous versions of the manuscript. All authors read and approved the final manuscript.

\section{Acknowledgements}

The authors would like to acknowledge the Defence Technology Agency, New Zealand Defence Force, for supporting this work; and Glynny Kieser for her editorial input.

\section{References}

Belmont, P. J., Jr., Goodman, G. P., Zacchilli, M., Posner, M., Evans, C., \& Owens, B. D. (2010). Incidence and epidemiology of combat injuries sustained during 'the surge' portion of operation iraqi freedom by a U.S. army brigade combat team. Journal of Trauma - Injury, Infection and Critical Care, 68(1), pp. 204-210.

Boyd, N. A. (1975). A military surgical team in Belfast. Annals of the Royal College of Surgeons of England, 56(1), pp. 15-25. 
Brady, C. G. (2003). An Analysis of Wound Statistics in Relation to Personal Ballistic Protection. Defence Science and Technology, Edinburgh.

Brayley, M. (2011). Modern Body Armour. The Crowwod Press, UK.

Breeze, J., Bowley, D. M., Naumann, D. N. (2020). Torso body armour coverage defined according to feasibility of haemorrhage control within the prehospital environment: a new paradigm for combat trauma protection. BMJ Mil Health Published Online First: 27 October 2020.

Breeze, J., Fryer, R. N., \& Lewis, E. (2021). Determining the optimum anatomical coverage of side plates for the VIRTUS body armour and load carriage system. BMJ Mil Health, 167(3), pp. 147-152.

Breeze, J., Lewis, E. A., \& Fryer, R. (2016b). Determining the dimensions of essential medical coverage required by military body armour plates utilising computed tomography. Injury, 47(9), pp. 1932-1938.

Breeze, J., Lewis, E., \& Carr, D. (2017). Ballistic Threats and Body Armour Design. In: Franklyn, M., \& Vee Sin Lee P. (eds.), Military Injury Biomechanics: The Cause and Prevention of Impact Injuries. CRC Press/Taylor \& Francis Group Boca Raton, FL, pp. 5-18.

Breeze, J., Lewis, E., Fryer, R., Hepper, A., Mahoney, P. F., \& Clasper, J. C. (2016a). Defining the essential anatomical coverage provided by military body armour against high energy projectiles. Journal of the Royal Army Medical Corps, 162(4), pp. 284-290.

Carr, D., \& Lewis, E. (2014). Ballistic-Protective Clothing and Body Armour. Protective Clothing: Managing Thermal Stress. F. Wang and C. Gao, Woodhead Publishing, pp. 146-170.

Herget, CM., Coe, GB., \& Beyer JC. (1962). Wound ballistics and body armour in Korea. Chapter 12 of Wound Ballistics. Accessed at: https://history.amedd.army.mil/booksdocs/wwii/ woundblstcs/chapter12.htm on 05 May 2021.

Hinsley, D. E., Rosell, P. A. E., Rowlands, T. K., \& Clasper, J. C. (2005). Penetrating missile injuries during asymmetric warfare in the 2003 Gulf conflict. BJS, 92(5), pp. 637-642.

Hopkins, J. (1962). Casualty Survey - New Georgia and Burma Campaigns. Chapter 4 of Wound Ballistics. Accessed at: https://history.amedd.army.mil/booksdocs/wwii/ woundblstcs/chapter4.htm on 05 May 2021.

Keene, D., Mahoney, P. F., Breeze, J., \& Ramasamy, A. (2017). The medical management of military injuries. In: Franklyn, M., \& Vee Sin Lee P. (eds.), Military Injury Biomechanics: The Cause and Prevention of Impact Injuries. CRC Press/Taylor \& Francis Group Boca Raton, FL, pp. 71-86.

Kosashvili, Y., Hiss, J., Davidovic, N., Lin, G., Kalmovic, B., Melamed, E., et al. (2005). Influence of personal armor on distribution of entry wounds: Lessons learned from urban-setting warfare fatalities. Journal of Trauma and Acute Care Surgery, 58(6), pp. 1236-1240.

Kotora, J. G., Henao, J., Littlejohn, L. F, \& Kircher, S. (2013). Vented chest seals for prevention of tension pneumothorax in a communicating pneumothorax. The Journal of Emergency Medicine, 45(5), pp. 686-694.

Lesquen, H. D., Beranger, F., Berbis, J., Boddaert, G., Poichotte, A., Pons, F., et al. (2016). Challenges in war-related thoracic injury faced by French military surgeons in Afghanistan (2009-2013). Injury, 47(9), pp. 1939-1944.

Lewis, E. A. (2006). Between Iraq and a Hard Plate: Recent Developments in UK Military Personal Armour. Paper read at
Personal Armour Systems Symposium 2006. 18-23 September. The Royal Armouries, Leeds, UK.

Lewis, E., \& Clarke, B. (2018). The virtues of VIRTUS: Development and introduction of the new VIRTUS body armour, load carriage and helmet system for UK Armed Forces personnel. Personal Armour Systems Symposium (PASS 2018). Washington DC, USA.

Littlejohn, L. F. (2017). Treatment of thoracic trauma: lessons from the battlefield adapted to all austere environments. Wilderness \& Environmental Medicine, 28(2s), pp. S69-s73.

Mabry, R. L., Holcomb, J. B., Baker, A. M., Cloonan, C. C., Uhorchak, J. M., Perkins, D. E. et al. (2000). United States army rangers in Somalia: An analysis of combat casualties on an urban battlefield. Journal of Trauma - Injury, Infection and Critical Care, 49(3), pp. 515-529.

Manring, M. M., Hawk, A., Calhoun, J. H., \& Andersen, R. C. (2009). Treatment of war wounds: a historical review. Clinical Orthopaedics and Related Research, 467(8), pp. 2168-2191.

Martin, M. J. (2015). Thoracic trauma in combat or austere environments. Current Respiratory Medicine Reviews, 11(1), pp. 17-29.

McNamara, J. J., Messersmith, J. K., Dunn, R. A., Molot, M. D., \& Stremple, J. F. (1970). Thoracic Injuries in Combat Casualties in Vietnam. Annals of Thoracic Surgery, 10(5), pp. 389-401.

Moffat, W., COL (1976). British forces casualties Northern Ireland. Journal of the Royal Army Medical Corps, 122, pp. 3-8.

Moore, R. A., Waheed, A., \& Burns, B. (2019). Rule of Nines. StatPearls Publishing LLC, Treasure Island, FL.

Oughterson, A., Hull, H., Sutherland, F., \& Greiner, D.J. (1962). Study on Wound Ballistics-Bougainville Campaign. Chapter 5 of Wound Ballistics. Accessed at https://history.amedd.army.mil/ booksdocs/wwii/woundblstcs/chapter5.htm on 05 May 2021.

Owens, B. D., Kragh, Jr, J. F., Wenke, J. C., Macaitis, J., Wade, C. E., \& Holcomb, J. B. (2008). Combat wounds in operation iraqi freedom and operation enduring freedom. Journal of Trauma Injury, Infection and Critical Care, 64(2), pp. 295-299.

Penn-Barwell, J. G., Sargeant, I. D., Penn-Barwell, J. G., Bennett, P. M., Fries, C. A., Kendrew, J. M., et al. (2016). Gun-shot injuries in UK military casualties - Features associated with wound severity. Injury, 47(5), pp. 1067-1071.

Poon, H., Morrison, J. J., Apodaca, A. N., Khan, M. A., \& Garner, J. P. (2013). The UK military experience of thoracic injury in the wars in Iraq and Afghanistan. Injury, 44(9), pp. 1165-1170.

Popivanov, G., Mutafchiyski, V. M., Belokonski, E. I., Parashkevov, A. B., \& Koutin, G. L. (2014). A modern combat trauma. Journal of the Royal Army Medical Corps, 160(1), p. 52.

Ramasamy, A., Harrisson, S., Lasrado, I., \& Stewart, M. P. M. (2009). A review of casualties during the Iraqi insurgency 2006 - A British field hospital experience. Injury, 40(5), pp. 493-497.

Roberts, G. K., \& Bullian, M. E. (1993). Protective ability of the standard U.S. Military Personal Armor System, Ground Troops (PASGT) fragmentation vest against common small arms projectiles. Military Medicine, 158(8), pp. 560-563.

Scallan, N. J., Keene, D. D., Breeze, J., Hodgetts, T. J., \& Mahoney, P. F. (2020). Extending existing recommended military casualty evacuation timelines will likely increase morbidity and mortality: a UK consensus statement. $B M$ J Military Health, 166(5), p. 287

Schauer, S. G., Naylor, J. F., Oliver, J. J., Maddry, J. K., \& April, M. D. (2019). An analysis of casualties presenting to military 
emergency departments in Iraq and Afghanistan. The American Journal of Emergency Medicine, 37(1), pp. 94-99.

Stevenson, T., Carr, D. J., Penn-Barwell, J. G., Ringrose, T. J., \& Stapley, S. A. (2018). The burden of gunshot wounding of UK military personnel in Iraq and Afghanistan from 2003-14. Injury, 49(6), pp. 1064-1069.

Tobin, L., \& Iremonger, M. (2006). Modern Body Armour and Helmets, Argos Press, Canberra, Australia.
Tribby, W. (1962). Examination of 1,000 American Casualties Killed in Italy. Chapter 6 of Wound Ballistics. Accessed at https:// history.amedd.army.mil/booksdocs/wwii/woundblstcs/ chapter6.htm on 05 May 2021.

Zouris, J. M., Walker, G. J., Dye, J., \& Galarneau, M. (2006). Wounding patterns for U.S. Marines and sailors during Operation Iraqi Freedom, major combat phase. Military Medicine, 171(3), pp. 246-252. 


\section{Appendix}

Tab. A1: Criteria for the modified Newcastle-Ottawa Scale regarding star allocation to assess quality of studies

\begin{tabular}{|c|c|c|}
\hline Criteria & Acceptable (star awarded) & Unacceptable (star not awarded) \\
\hline Representativeness of exposed cohort $\left(^{*}\right)$ & Population based & $\begin{array}{l}\text { Hospital based } \\
\text { Civilians included }\end{array}$ \\
\hline Ascertainment of exposure $\left({ }^{\star}\right)$ & Trauma records & Anecdotal evidence \\
\hline Comparability $(* \star)$ & $\begin{array}{l}\text { ** awarded for both number of casualties and } \\
\text { number of fatalities comparable } \\
\text { * awarded for only one metric comparable }\end{array}$ & No metrics comparable \\
\hline Assessment of outcome $\left(^{\star}\right)$ & Trauma records & No outcome data \\
\hline
\end{tabular}

Tab. A2: Quality assessment of studies using a modified Newcastle Ottawa Scale for assessing studies in the systematic review of military thoracic gunshot injuries

\begin{tabular}{|c|c|c|c|c|c|}
\hline & Selection & & Comparability & Outcome & Total score $\left(5^{\star}\right)$ \\
\hline Study ID & $\begin{array}{l}\text { Representativeness of } \\
\text { exposed cohort }\left(^{*}\right)\end{array}$ & $\begin{array}{l}\text { Ascertainment } \\
\text { of exposure }(*)\end{array}$ & $(* \star)$ & $\begin{array}{c}\text { Assessment of } \\
\text { outcome }\left(^{*}\right)\end{array}$ & \\
\hline (Herget et al. 1962) & * & * & * & & 3 \\
\hline (Hopkins 1962) & * & * & $\star \star$ & * & 5 \\
\hline (Oughterson et al. 1962) & * & * & * & & 3 \\
\hline (Tribby 1962) & * & * & $\star \star$ & * & 5 \\
\hline (McNamara et al. 1970) & * & * & * & & 3 \\
\hline (Boyd 1975) & * & * & $\star \star$ & * & 5 \\
\hline (Moffat 1976) & * & * & ** & * & 5 \\
\hline (Mabry et al. 2000) & * & * & * & & 3 \\
\hline (Brady 2003) & * & * & * & * & 4 \\
\hline (Kosashvili et al. 2005) & * & * & * & & 3 \\
\hline (Hinsley et al. 2005) & & * & * & & 2 \\
\hline (Lewis 2006) & * & * & ** & * & 5 \\
\hline (Zouris et al. 2006) & * & * & * & & 3 \\
\hline (Owens et al. 2008) & * & * & * & & 3 \\
\hline (Ramasamy et al. 2009) & * & * & * & & 3 \\
\hline (Belmont Jr et al. 2010) & * & * & * & & 3 \\
\hline (Poon et al. 2013) & * & * & * & & 3 \\
\hline (Popivanov et al. 2014) & & * & * & & 2 \\
\hline (Martin 2015) & * & * & & & 2 \\
\hline (Lesquen et al. 2016) & & * & * & & 2 \\
\hline (Penn-Barwell et al. 2016) & * & * & ** & * & 5 \\
\hline (Stevenson et al. 2018) & * & * & $\star \star$ & * & 5 \\
\hline (Schauer et al. 2019) & & * & * & & 2 \\
\hline
\end{tabular}

Total score: $1-2$ poor quality, $3=$ fair quality, $4-5=$ Good quality 
Tab. A3: Risk of bias assessment using a modified Cochrane Tool

\begin{tabular}{|c|c|c|c|c|c|c|}
\hline Study ID & $\begin{array}{c}\text { Allocation } \\
\text { concealment } \\
\text { (Selection bias) }\end{array}$ & $\begin{array}{c}\text { Assessment } \\
\text { of exposure } \\
\text { (Performance bias) }\end{array}$ & $\begin{array}{l}\text { Outcome of interest } \\
\text { present at beginning } \\
\text { (detection bias) }\end{array}$ & $\begin{array}{c}\text { Incomplete } \\
\text { data } \\
\text { (attrition bias) }\end{array}$ & $\begin{array}{c}\text { Selective } \\
\text { reporting } \\
\text { (reporting bias) }\end{array}$ & $\begin{array}{c}\text { Total } \\
\text { score* }\end{array}$ \\
\hline (Herget et al. 1962) & + & + & + & $?$ & $?$ & 3 \\
\hline (Hopkins 1962) & + & + & + & + & $?$ & 4 \\
\hline (Oughterson et al. 1962) & + & + & + & $?$ & $?$ & 3 \\
\hline (Tribby 1962) & + & + & + & $?$ & $?$ & 3 \\
\hline (McNamara et al. 1970) & + & + & + & $?$ & $?$ & 3 \\
\hline (Boyd 1975) & + & + & + & + & $?$ & 4 \\
\hline (Moffat 1976) & + & + & + & + & $?$ & 4 \\
\hline (Mabry et al. 2000) & + & + & + & $?$ & $?$ & 3 \\
\hline (Brady 2003) & + & + & + & $?$ & $?$ & 3 \\
\hline (Kosashvili et al. 2005) & + & + & + & $?$ & $?$ & 3 \\
\hline (Hinsley et al. 2005) & - & + & + & $?$ & $?$ & 2 \\
\hline (Lewis 2006) & + & + & + & $?$ & $?$ & 3 \\
\hline (Zouris et al. 2006) & + & + & + & $?$ & $?$ & 3 \\
\hline (Owens et al. 2008) & + & + & + & $?$ & $?$ & 3 \\
\hline (Ramasamy et al. 2009) & + & + & + & $?$ & $?$ & 3 \\
\hline (Belmont Jr et al. 2010) & + & + & + & $?$ & $?$ & 3 \\
\hline (Poon et al. 2013) & + & + & + & ? & $?$ & 3 \\
\hline (Popivanov et al. 2014) & - & + & + & $?$ & $?$ & 2 \\
\hline (Martin 2015) & + & + & + & $?$ & $?$ & 3 \\
\hline (Lesquen et al. 2016) & - & + & + & ? & $?$ & 2 \\
\hline (Penn-Barwell et al. 2016) & - & + & + & + & $?$ & 3 \\
\hline (Stevenson et al. 2018) & + & + & + & + & $?$ & 4 \\
\hline (Schauer et al. 2019) & + & + & + & $?$ & $?$ & 3 \\
\hline
\end{tabular}

$\pm=$ Low risk of bias, $?=$ Unclear risk of bias, $\mathbf{m}=$ High risk of bias.

*Total score $=$ Points awarded based on number of low risks of bias. 1-2= High risk of bias, $3=$ unclear risk of bias 4-5=low risk of bias 